\title{
The Influence of Situation-Dependent Factors on Mobile Shopping Usage
}

\author{
Larissa Wolf \\ ESCP Europe \\ Business School, Berlin \\ lwolf@escpeurope.eu
}

\author{
Markus Bick \\ ESCP Europe \\ Business School, Berlin \\ mbick@escpeurope.eu
}

\author{
Tyge-F. Kummer \\ Griffith University \\ t.kummer@griffith.edu.au
}

\begin{abstract}
Although situations influence the use of a technology, this field has been largely neglected in mobile shopping. Therefore, this paper aims to identify situational factors impacting on the intention to use a mobile device for actual purchase transactions, as actual purchases were found to be the least adapted shopping activity conducted via mobile devices. This study contributes to the field of mobile shopping behavior by being the first to simultaneously investigate the influence of various situational factors on the intention to shop mobile. Based on Belk's five categories of situational factors, we perform a conjoint analysis to explore the relevance of different situational characteristics for low and high involvement products. The results indicate that particularly the product price, the internet connection, and the mobile shop layout determine mobile shopping behavior. Practical actions to strengthen the mobile channel and increase consumers' intentions to purchase via mobile devices, can be derived from the findings.
\end{abstract}

\section{Introduction}

For several years, traditional online retailing, meaning e-commerce, has influenced consumers' shopping opportunities and behavior, thus, challenging more conventional retail channels like actual stores [1, 2]. Obviously, mobile shopping, using a mobile device for purchase activities, is on the advance and is influencing consumers' shopping opportunities. This development has been due to the growth of mobile internet and the evolution of the cell phone from a simple communication tool, with call and text functions, to a smartphone, an almost all-rounder. The number of smartphone users worldwide is expected to grow to 2.08 billion in 2016 and to increase to 2.66 billion in 2019 [3]. Besides, new mobile devices like tablets, and more recently wearables, were put on the market enabling consumers to be online all of the time while being embedded in smart environments at the same time
[4]. Such mobile devices have changed the way of shopping [5], as they are portable, provide a personal relationship with the owner, provide networked and immediate information, deliver textual as well as visual content, converge functions [6]. Consumers are increasingly using mobile devices in order to research products and services, discover new products and follow brands [7]. Moreover, mobile devices can be used to support in-store or other channel purchases, for example by searching for a local retailer or coupons, communicating with others about a product, checking a product's availability at a store, or comparing prices, but can also work as a point of sale itself [8]. Hence, it is not surprising that one third of online purchases in the USA take place via a mobile device [9].

To understand the usage of a corresponding technology, it is crucial to analyze the diverse influencing variables. Previous research especially shed light on the technology characteristics themselves to explain mobile shopping behavior [10]. Whereas consumer characteristics have been partially analyzed [10]. However, another factor which possibly influences mobile shopping usage has been largely neglected so far - situational factors. Situational or contextual factors are highly relevant in commerce as shopping behavior always appears within a specific context [11-13]. In contrast to actual stores or stationary internet, the mobile internet provides services anywhere and anytime [14]. Mobile internet can be used in various situations, whereas these situations are somehow limited for other channels [15]. Therefore, understanding in which situations consumers shop mobile is particularly useful. Groß [10] explicitly stated the lack of situational research in mobile shopping and thus, recommended the investigation of situations with regard to mobile shopping. In this study, we use Belk's [16] five categories of situational factors as a foundation in order to investigate factors influencing consumer's decision to use the mobile channel for purchasing. 
The paper is structured as follows. In section 2 the related literature is presented. Then, we derive the research model in section 3 . Methodological aspects are outlined in section 4 . Section 5 provides an overview of the results. The findings are discussed in section 6 before we conclude with section 7 .

\section{Related Literature}

\subsection{Mobile Shopping}

Mobile commerce is based on mobile services and contains mobile shopping, mobile financial services, mobile entertainment and mobile information [17]. Mobile commerce can take place on business-tobusiness, business-to-consumer and consumer-toconsumer level [17, 18]. Mobile services are provided through mobile devices and wireless networks, and thus, customers and vendors can be accessed without constraints [5]. Moreover, mobile services can also adjust to user-specific conditions, which services provided by other channels cannot do in the same manner [19]. The inherent characteristics of mobile services comprise ubiquity, personalization, flexibility, and dissemination [20].

Finally, mobile shopping could be defined as "any monetary transaction related to purchases of goods or services through internet enabled mobile phones or over the wireless telecommunication network" [21]. Mobile shopping uses web sites, including various features such as product searches, price comparisons, ordering, paying, after-services [22]. According to Yang [23], mobile shopping can optimize consumers' shopping experience across channels through various features. It is seen as an additional shopping channel and as a personal shopping assistant transforming consumer shopping experiences in stores to the following optimized shopping experiences across channels: “a.) creating a real-time interaction between retailer and consumer; b.) assisting a consumer in making smart purchasing decisions by providing customized product/service information; and c.) delivering non-intrusive mobile marketing to consume." We conclude that mobile shopping provides several advantages, such as ubiquity, flexibility, personalization, accessibility, dissemination, convenience and mobility, thus enabling consumers to shop anytime and anywhere and to save time [21, 24, 25].

\subsection{Adoption Factors of Mobile Shopping}

Research on mobile shopping has focused particularly on its relevance as a distribution channel and addresses particularly the technology adoption
[10]. Most of the studies which have researched mobile shopping adoption and its determinants build on one or on a combination of existing technology acceptance theories like the Technology Acceptance Model (TAM) etc. [26]. Wu and Wang [27], for instance, used a revised TAM to explain the user acceptance of mobile commerce. Their findings suggest that perceived risk, perceived cost, compatibility and perceived usefulness influence user acceptance [27]. Aldás-Manzano, Ruiz-Mafé and Sanz-Blas [28] extended the TAM to examine three personality variables related to technology, namely innovativeness, compatibility and affinity. Each variable was found to have a positive effect on mobile shopping use intention. Similarly Agrebi and Jallaisb [29] extended TAM and confirmed the influence of perceived enjoyment and satisfaction on the usage intention. Several further TAM extensions exist (e.g., [21, 25, 30]). Overall, this research stream seems to be exhausted and the results depend highly on the scenario and the context. Saying this, we focus on the situational factors that are independent from the user.

\subsection{Situational factors}

Situations are defined as [...] "all those factors particular to a time and place of observation which do not follow from a knowledge of personal (intra-individual) and stimulus (choice alternative) attributes, and which have a demonstrable and systematic effect on current behavior." [31]. This definition makes clear that person, situation and stimulus object are different causes influencing behavior $[11,16,32]$. The aforementioned definition by Belk [31] further excludes (broad) environmental factors, which are not particular to the place and time, where and when the situation occurs.

Cote, McCullough and Reilly [33] demonstrated that differences between intention and behavior of product consumption are partly due to unexpected situations, and thus proving that situations influence behavior. Sandell [34] found that situational factors, separately or alongside other factors, are responsible for $73 \%$ of the total variation in drink choice. From traditional retail it is known that money availability, friendly store employees, credit card use and age affect impulsive buying behavior [12]. However, situational factors such as time pressure in relation to online daily deals and social pressure also influence compulsive buying behavior [13]. Belk [16] identified five categories of situational factors that will be used as foundation in our study: 
1. Physical surroundings: These are the most readily apparent features (e.g., location, weather, and visible configurations of merchandise[16]).

2. Social surroundings: This aspect includes "other persons present, their characteristics, their apparent roles, and interpersonal interactions occurring” [16] (e.g., sales people characteristics can influence the purchase result [35]).

3. Temporal perspective: This incorporates factors such as the time of day, time since or leading up to an event, time when most recent purchase was made, or time limitations. The distance and time it takes to get to a specific location can also be a temporal factor [36]. Roslow, Li and Nicholls [37] found that season, as a temporal perspective, influenced various aspects of shopping behavior. Park, Iyer and Smith [38] demonstrated that time available for shopping is a situational factor influencing shopping behaviors as well.

4. Task definition: The intention "to select, shop for, or obtain information about a general or specific purchase” [16] (e.g., buying different products for oneself or as a gift makes a difference [16]). Consumer behavior is influenced by the shopping motivation and consumers who have planned specific purchases tend to buy rather than those who have not planned on buying [39].

5. Antecedent states: This dimension covers "momentary moods (such as acute anxiety, pleasantness, hostility, and excitation) or momentary conditions (such as cash on hand, fatigue, and illness)" [16] influencing a consumer's choice.

\section{Hypothesis development}

The framework of five categories of situational factors (section 2.2) provides the theoretical foundation for this study. In the following we derive corresponding hypothesis based on this framework by Belk [16] and focus on particular characteristics of mobile shopping.

A clear app or mobile web site makes the information search and product finding process easier [40]. This is part of the physical surroundings and replaces the traditional store layout of brick and mortar shops as configurations of merchandise. Formally, we state:

H1: The clearer the mobile web site or app layout, the higher the probability of mobile shopping.
If no alternative sales channel such as a physical store or a traditional personal computer for online shopping is available, this will likely lead to an increased mobile shopping behavior. This covers particularly the location aspect, but is further linked to the temporal perspective as we assume that willingness for mobile purchasing behavior is increased when alternative channels are not directly available. Similarly, self-service technologies in retail are used more frequently by customers when alternative sales channels are not directly available [41]. Therefore, we state:

H2: If no channel alternative is available (promptly and nearby), the probability of mobile shopping increases.

Time available is also part of the temporal perspective. Chocarro, Cortiñas and Villanueva [40], showed successfully a connection between the available time and the purchase channel. Smartphones are available immediately as most users wear them always (see section 1). The immediate availability makes them ideal for fast shopping activities. We state:

H3: The less time a shopper has available, the greater the probability of mobile purchase.

Mobile services are often used while doing other activities. This includes particularly leisure activities such as watching TV [42]. This can be linked to the antecedent state. The corresponding momentary moods can be descripted as being bored or lazy. We state:

H4: The lazier an individual is in a certain situation, the greater the probability of mobile shopping.

In order to use mobile shopping the physical surrounding has to provide internet access. Previous results in e-commerce suggest that if the internet connection is slow than this will affect the shopping experience negatively [43]. As a result, we propose that the internet connection will determine whether consumers shop using a mobile device or not.

H5: The better the internet connection available for one's mobile device, the greater the probability of mobile purchase.

Furthermore, the task definition construct can be used to determine another influence factor. If the user 
is currently conducting a task utilizing a mobile device then this can trigger a related purchase activity. For instance, it might be that an individual reads about a particular product on a mobile device. Then it is likely that this task leads to a connected mobile shopping activity as it is more convenient for the user to proceed with the same device $[44,45]$.

H6: Using a mobile device when getting into a purchase situation increases the probability of mobile shopping.

Situation-dependent costs of purchasing, including the actual product price as well as additional costs, have been found to play a substantial role in purchase decisions [46]. According to Belk's categories the price can be assigned to the physical surrounding as it is part of the visible configuration of merchandise. We assume that the product price will influence mobile shopping behavior. If mobile purchases allow for cost savings, consumers prefer to use the mobile channel. We state:

H7: The more money shoppers can save by purchasing using mobile devices, the greater the probability of mobile purchase.

\section{Experimental Design}

A modified experimental design following Chocarro, Cortiñas and Villanueva [40], who investigated the probability of online shopping, was chosen. Respondents had to imagine various situations and had to rate their intention to purchase two different products using mobile shopping for each of those situations. A within-subject method was used for both investigating situational factor influences and examining the moderating effect of product category.

\subsection{Situational context}

The situations were constructed by using the situational factors defined in section 3 . These situational factors are manipulated from one situational scenario to another. In this way, hypothesized causal effects between the independent situational factors and the dependent variable probability to purchase mobile can be identified [47]. In order to construct situational scenarios, a fullprofile approach was chosen. All seven selected factors are utilized for the situation descriptions [48]. This allows for the simultaneous examination of various situational factors. However, level definition of situational factors might lead to information overload and is a considerable risk of the full-profile method [48]. Thus, a limited number of factor levels has to be defined. Two levels are given to each of the seven factors in order to restrict the possible number of situational scenarios [40]. This way, feasibility can be ensured. Table 1 summarizes the seven factors and the two related levels.

Table 1: Situational factors and factor levels

\begin{tabular}{|l|c|c|}
\hline Situational factor & Factor level 1 & Factor level 2 \\
\hline $\begin{array}{l}\text { Mobile shop } \\
\text { layout }\end{array}$ & Clear & Not very clear \\
\hline $\begin{array}{l}\text { Availability of } \\
\text { alternative } \\
\text { shopping channel }\end{array}$ & $\begin{array}{c}\text { Yes, prompt } \\
\text { \& nearby }\end{array}$ & $\begin{array}{c}\text { No, not before } \\
\text { tomorrow }\end{array}$ \\
\hline Time availability & Little time & Plenty of time \\
\hline $\begin{array}{l}\text { Level of activity } \\
\text { Lazy }\end{array}$ & $\begin{array}{l}\text { Active \& } \\
\text { vigorous }\end{array}$ \\
\hline $\begin{array}{l}\text { Internet } \\
\text { connection on } \\
\text { mobile device }\end{array}$ & Good & Bad \\
\hline $\begin{array}{l}\text { Situational } \\
\text { mobile device } \\
\text { usage }\end{array}$ & $\begin{array}{c}\text { Yes } \\
\text { Same price as } \\
\text { purchasing }\end{array}$ & $\begin{array}{c}10 \% \text { less via } \\
\text { mobile } \\
\text { channel }\end{array}$ \\
\hline
\end{tabular}

When using a full-profile method, the total amount of profiles is large [48]. All possible combinations of the selected seven situational factors and their corresponding levels result in 128 different situational scenarios [40]. To make it feasible for the respondents to manage the rating task, the number of scenarios to be rated, need to be decreased without restricting the examination power of the study [40]. Thus, a fractional factorial design was used to decrease the possible combination amount to a manageable number [48]. Following the procedure of Chocarro, Cortiñas and Villanueva [40] an orthogonal design approach was chosen to select exemplary appropriate situational scenarios, which make the rating task easier, but nevertheless allow for estimating all important effects [40]. As a result, 8 representative situational scenarios with different combination of the seven factors were generated that build the foundation of the conjoint analyses.

\subsection{Choice of products}

Shopping behavior is usually influenced by the product (e.g. [12], [13], [40]). Therefore, we control for high and low involvement in order to increase external validity of our results [40]. The two products 
selected have different involvement levels and furthermore, they are products that consumers frequently purchase mobile to ensure that respondents are familiar with the situation and product [40]. We selected clothes as low involvement products and technical items as high involvement products. Both are experience goods, therefore it can be ensured that these influences do not distort the study's results. Chocarro, Cortiñas and Villanueva [40] determined a t-shirt to be a low involvement good and the interviewees agree as they have stated that they order clothes mobile quite often. Moreover, those interviewees have mentioned using shops such as $\mathrm{H} \& \mathrm{M}$ or Zara, which are fast fashion producers and thus, perceiving it as low involvement seems appropriate. For this reason the two selected products are a t-shirt and a laptop. They were chosen, because they are both very general everyday objects, and are not products that are related to gender or any other demographic characteristics.

\subsection{Data collection}

It was decided to administer this study through a self-completion questionnaire using an internet-based survey platform. This has advantages like low costs, potential respondents can be easily contacted independently from geographical distances, it offers quick completion and a relatively large amount of data can be collected in a short time [49]. Answering every question was a condition that was imposed in order to submit the questionnaire. This ensures that no values are left blank. One of the major disadvantages of online questionnaires is that people without internet access cannot participate [49]. However, this is not relevant to this study, because using mobile shopping requires internet access anyway. Google Forms was chosen as a survey platform, as the features are sufficient for this questionnaire, it is easy to use, free of charge and can be completed using a computer as well as a mobile device.

Before the questionnaire was finally launched, a pilot test with three respondents was conducted. This led to some minor changes to the layout, which improved recognizing the different levels of each situational factor when reading the various situational scenarios. Moreover, the feedback resulted in the exclusion of holdout cases because all three test respondents complained about the length of the questionnaire. The final questionnaire length is approximately 15 minutes and was accessible online for 18 days in April 2016.

The questionnaire began with a definition of mobile shopping followed by an explanation what participants were to expect and assurance of confidentiality. Respondents were asked to rate their mobile purchase intention for two different products, a t-shirt and a laptop, in eight different situations. Thus, in total they had to rate the appropriateness of sixteen situational scenarios for mobile shopping. After finishing the rating task, respondents were asked if they had already purchased something via a mobile device and to provide some demographic data. The scenarios had to be rated on a Likert scale from 1 to 5 . The lower end point of the scale means "I would definitely not purchase mobile", whereas the upper end point states "I would definitely purchase mobile”.

\subsection{Sample}

The link to the online self-completion questionnaire was shared on Facebook and was also sent out to acquaintances via e-mail. No financial incentives were provided. In a further step, with the help of snowball sampling, additional respondents were recruited [50]. As a result, questionnaire participants shared the link with their acquaintances on Facebook.

The questionnaire was accessed and submitted by a total of 106 persons. Of these, 12 had to be excluded from further analysis, because the response time was less than half of the average completion time. These responses further indicated almost no variance between different products and purchase situations indicating that these 12 participants did not read the descriptions and had responded rather arbitrarily. Hence, 94 eligible respondents remained (Table 2).

Table 2: Characteristics of Respondents

\begin{tabular}{|l|r|r|}
\hline \multicolumn{1}{|c|}{ Aspect } & \multicolumn{1}{|c|}{ Response } & Percentage \\
\hline Already purchased & Yes & $77.7 \%$ \\
\cline { 2 - 3 } mobile & No & $22.3 \%$ \\
\hline Age & Ø in years & $32.6 Y$ \\
\hline \multirow{2}{*}{ Nationality } & German & $90.3 \%$ \\
\hline \multirow{4}{*}{ Gender } & Other & $9.7 \%$ \\
\hline \multirow{4}{*}{$\begin{array}{l}\text { Population of } \\
\text { place of residence }\end{array}$} & Male & $54.3 \%$ \\
\cline { 2 - 3 } & $>1,000,000$ & $45.7 \%$ \\
\cline { 2 - 3 } & $500,000-$ & $30.8 \%$ \\
\cline { 2 - 3 } & $1,000,000$ & $6.4 \%$ \\
\cline { 2 - 3 } & $200,000-499,999$ & $16.0 \%$ \\
\cline { 2 - 3 } & $50,000-199,999-99,999$ & $12.7 \%$ \\
\cline { 2 - 3 } & $20,000-49,999$ & $4.3 \%$ \\
\cline { 2 - 3 } & $5,000-19,999$ & $8.5 \%$ \\
\cline { 2 - 3 } & $1,000-4,999$ & $9.6 \%$ \\
\cline { 2 - 3 } & $<1,000$ & $0.0 \%$ \\
\hline
\end{tabular}




\begin{tabular}{||c|r|r|}
\hline \multirow{4}{*}{ Education } & $\begin{array}{r}\text { School } \\
\text { Professional } \\
\text { degree }\end{array}$ & $20.2 \%$ \\
\cline { 2 - 3 } & $\begin{array}{r}\text { Bachelor's } \\
\text { degree }\end{array}$ & $33.8 \%$ \\
\cline { 2 - 3 } & Master's degree & $27.8 \%$ \\
\cline { 2 - 3 } & Doctorate degree & $2.1 \%$ \\
\cline { 2 - 3 } & Other & $2.1 \%$ \\
\hline
\end{tabular}

Among the participants we find people with following nationalities: German, German-American, American, French, Spanish, Croatian, Austrian, and Indian. Regarding age, the youngest respondent was 18 and the oldest 73.

\subsection{Data analysis}

Two different conjoint analyses were conducted. One was conducted using the ratings for the t-shirt purchase situations, whereas the other was conducted for the laptop purchase situations. Respondents of both groups were the same. Both conjoint analyses were conducted by using SPSS 22.

Based on the mobile purchase probability ratings for the various situational scenarios, part worths, also called utility, can be estimated for each situational factor level [51]. The basis for estimating part worths is a preference function stating the expected relation between factors and ratings [48]. There are different models. Because all situational factors are categorical, the part worth model is used for all factors [48]. By summing up the part worths, a total utility for the mobile shopping appropriateness of each situation can be estimated. The study applies OLS (Ordinary Least Squares) regression. It aims at reducing squared deviations between stated and estimated part worths [51]. The dependent variable is the situational rating and the independent variables are the situational factors and their levels. Studies have demonstrated that OLS analyses basically lead to the same results as non-metric techniques and thus, it can be seen as a tried and tested and convenient approximation of the actually preferable non-metric methods [48]. The additive model has to be expanded by incorporating a constant $(\mu)$, which is a basis utility from which factor levels deviate positively or negatively [51]. Furthermore, as we do not focus on individual scores an aggregated conjoint analysis is performed.

\section{Results}

The results of the conjoint analysis contain the utility estimates of every factor level. For both conjoint analyses using OLS regression the outcomes are presented in Table 3, which lists the utility estimates for every level of each situational factor.

Part worths determine the preferred direction of a particular factor for supporting mobile shopping. Higher part worths indicate greater preference [51]. Thus, levels with positive part worths are preferred over the negative ones and increase the probability of mobile shopping. Averaged importance scores of factors refer to how much a certain factor can influence consumers' preference (Backhaus et al., 2015). Thus, for example a low averaged importance means that the factor is not as important as a factor with a high averaged importance for determining whether a consumer will shop mobile or not.

Table 3: Aggregated Utility Estimates of Factor Levels by Product

\begin{tabular}{|c|c|c|c|}
\hline & & T-Shirt & Laptop \\
\hline Factor & Level & $\begin{array}{c}\text { Utility } \\
\text { Estimate }\end{array}$ & $\begin{array}{c}\text { Utility } \\
\text { Estimate }\end{array}$ \\
\hline \multirow{2}{*}{$\begin{array}{l}\text { Mobile shop } \\
\text { layout }\end{array}$} & Clear & 0.249 & 0.231 \\
\hline & Not very clear & -0.249 & -0.231 \\
\hline \multirow{2}{*}{$\begin{array}{l}\text { Availability } \\
\text { of alternative } \\
\text { shopping } \\
\text { channel }\end{array}$} & $\begin{array}{l}\text { Yes, prompt } \\
\text { \& nearby }\end{array}$ & -0.089 & 0.019 \\
\hline & $\begin{array}{c}\text { No, not before } \\
\text { tomorrow }\end{array}$ & 0.089 & -0.019 \\
\hline \multirow{2}{*}{$\begin{array}{l}\text { Time } \\
\text { availability }\end{array}$} & Plenty of time & -0.041 & -0.024 \\
\hline & Little time & 0.041 & 0.024 \\
\hline \multirow{2}{*}{$\begin{array}{l}\text { Level of } \\
\text { activity }\end{array}$} & $\mathrm{La}$ & -0.033 & 0.003 \\
\hline & $\begin{array}{l}\text { Active \& } \\
\text { vigorous }\end{array}$ & 0.033 & -0.003 \\
\hline \multirow{2}{*}{$\begin{array}{l}\text { Internet } \\
\text { connection }\end{array}$} & Good & 0.307 & 0.247 \\
\hline & Bad & -0.307 & -0.247 \\
\hline \multirow{2}{*}{$\begin{array}{l}\text { Situational } \\
\text { mobile } \\
\text { device use }\end{array}$} & Yes & 0.062 & 0.019 \\
\hline & No & -0.062 & -0.019 \\
\hline \multirow{2}{*}{$\begin{array}{l}\text { Cost for } \\
\text { purchasing }\end{array}$} & $10 \%$ less & 0.416 & 0.529 \\
\hline & Same price & -0.416 & -0.529 \\
\hline (Constant) & & 2.757 & 2.476 \\
\hline
\end{tabular}

Table 4 shows the relative situational factor importance for both products' purchases. Both part worths estimates, as well as averaged importance, are used for discussing the stated hypotheses. These results are presented in the following section.

Table 4: Averaged Importance of Factors

\begin{tabular}{|r|r|r|}
\hline & T-Shirt & Laptop \\
\hline Factor & $\begin{array}{c}\text { Averaged } \\
\text { Importance }\end{array}$ & $\begin{array}{c}\text { Averaged } \\
\text { Importance }\end{array}$ \\
\hline Mobile shop layout & $18.836 \%$ & $16.167 \%$ \\
\hline $\begin{array}{r}\text { Availability of } \\
\text { alternative shopping }\end{array}$ & $10.226 \%$ & $9.175 \%$ \\
\hline
\end{tabular}




\begin{tabular}{|r|r|r|}
\hline channel & & \\
\hline Time availability & $10.339 \%$ & $9.745 \%$ \\
\hline Level of activity & $11.588 \%$ & $8.846 \%$ \\
\hline $\begin{array}{r}\text { Internet connection } \\
\text { device use }\end{array}$ & $17.532 \%$ & $14.421 \%$ \\
\hline Cost of purchasing & $22.022 \%$ & $32.031 \%$ \\
\hline
\end{tabular}

In accordance with hypothesis $\mathrm{H} 1$, a clearer mobile shop design generally seems to increase the probability of mobile shopping. Table 3 shows that for the purchase situation of both products, a clear mobile shop design has positive utility estimates $(+0.249$ for t-shirt and +0.231 for laptop), whereas a design that is not very clear has negative utility estimates ( -0.249 for $t$-shirt and -0.231 for laptop). The utility estimates are not very close to zero. Thus, on average consumers seem to clearly prefer a clearer design for shopping mobile. As Table 4 shows the averaged importance of the situational factor mobile shop layout is higher for the t-shirt purchase situation (18.836\%) than for the laptop purchase situation (16.167\%). However, the t-test result indicates that differences in averaged importance score between both product groups are statistically not significant with $\mathrm{t}(93)=1.504$ at $\mathrm{p}=0.136$.

Regarding hypothesis H2 no clearly supporting findings can be derived. In the t-shirt purchase situation, consumers would apparently rather shop mobile in case no alternative channel is available promptly and nearby (utility estimate of +0.089 for no alternative available versus -0.089 for alternative available). This is in line with hypothesis $\mathrm{H} 2$. However, utility estimates indicate that consumers would rather purchase a laptop mobile if an alternative channel is available promptly and nearby (utility estimate of +0.019 for alternative available versus - 0.019 for no alternative available). This contradicts hypothesis H2. The utility estimates for the laptop purchase situation are very close to zero. This makes the context more complex. The closer the utility estimate is to zero, the more uncertain is the assumption that one factor level is preferred over the other. It could be that the negative sign, by chance, fell into one direction, and the factor has no important influence. However, the factor's averaged importance score of $9.175 \%$ for the laptop purchase situation does not support this assumption. Therefore, it could be that respondents are heterogeneous regarding the alternative channel availability in the laptop purchase situation, and that different subgroups with different preferences exist. This means that some would rather shop for a laptop mobile if no alternative channel is available, whereas others would rather shop for a laptop mobile if an alternative channel is available, leading to a rather random allocation of the plus and minus sign. These different preferences could be due to the general higher monetary value of a high involvement good when compared to a low involvement good. However, it is hard to interpret those values reliably. The t-test indicates that the difference in the averaged importance scores between the two involvement levels is statistically not significant with $\mathrm{t}(93)=0.900$ at $\mathrm{p}=0.370$.

The findings of both conjoint analyses seem to support hypothesis H3. For both products' purchase situations the utility estimates are higher for little time available $(+0.041$ for t-shirt and +0.024 for laptop) than for plenty of time available ( -0.041 for tshirt and -0.024 for laptop). To a certain degree it is plausible to assume that the less time a shopper has available, the greater the probability of mobile shopping. However, the utility estimates for both products are close to zero, which again, makes it doubtful that these values can be interpreted reliably. Utility estimates close to zero in combination with averaged importance scores of approximately 10\% suggest that consumers are heterogeneous. Some prefer mobile shopping when they only have a small amount of time available, whereas others prefer mobile shopping when they have plenty of time. Thus, there seems to be no general and valid trend across all consumers that a lack of time increases the mobile shopping probability. Hence, hypothesis H3 cannot be supported through the conjoint analyses. The averaged importance of the situational factor time availability is $10.339 \%$ for the t-shirt purchase, whereas for the laptop purchase it is $9.745 \%$. The ttest indicates that the difference is statistically not significant with $\mathrm{t}(93)=0.442$ at $\mathrm{p}=0.659$.

Hypothesis $\mathrm{H} 4$ - that the lazier an individual is in a certain situation, the greater the probability of mobile shopping - cannot be supported by the findings of the conjoint analyses. According to Table 3 , when purchasing a t-shirt, consumers apparently prefer shopping mobile when being active and vigorous. For the purchase situation of a t-shirt, the utility estimate for mobile shopping when being lazy is -0.033 , whereas it is +0.033 when feeling active and vigorous. However, the values are again close to zero. For the laptop purchase situation, the utility estimates are almost zero. The utility estimate for shopping mobile for a laptop - when being lazy - is +0.003 and -0.003 when feeling active and vigorous. Therefore, the findings cannot support hypothesis H4 and it is difficult to interpret these results reliably. As described previously, a follow-up analysis could be helpful. Level of activity seems to be more relevant on the mobile shopping probability for low 
involvement than for high involvement goods, because level of activity has an averaged importance score of $11.588 \%$ in the t-shirt purchase situation, whereas this score is $8.846 \%$ in the laptop purchase situation. However, the t-test result indicates that the difference of $2.742 \%$ is statistically not significant with $\mathrm{t}(93)=2.104$ at $\mathrm{p}=0.038$.

The conjoint analyses findings promote hypothesis $\mathrm{H} 5$ that the better the internet connection on a mobile device, the higher the probability of mobile purchase. For the purchase situations of both products, good internet connection on mobile device has a higher utility estimate (for t-shirt +0.307 and for laptop +0.247) than bad internet connection (for tshirt -0.307 and for laptop -0.247). The averaged importance of internet connection is $17.532 \%$ in the t-shirt purchase situation, whereas it is $14.421 \%$ for the purchase of a laptop. However, the t-test result indicates the difference of $3.111 \%$ to be statistically not significant with $\mathrm{t}(93)=2.075$ at $\mathrm{p}=0.041$.

In accordance with hypothesis H6, situational mobile device usage generally seems to increase the probability of mobile shopping, because for both products' purchase situations, situational mobile device usage has a positive utility estimate (for t-shirt +0.062 and for laptop +0.019 ). These utility estimates are negative for no situational mobile device usage (for t-shirt -0.062 and for laptop -0.019). The effect of situational mobile device usage seems to be rather small. The averaged importance of situational mobile device usage for both purchase situations is almost the same. For the t-shirt purchase it is $9.457 \%$ and for the laptop purchase it is $9.616 \%$. The difference is statistically not significant with $\mathrm{t}(93)=-0.131$ at $\mathrm{p}=$ 0.896 .

Both conjoint analyses clearly support hypotheses $\mathrm{H} 7$ that generally the more money shoppers can save by purchasing mobile, the greater the probability of mobile purchase. This situational factor seems to be the most important one. The utility estimate for saving $10 \%$, compared to other shopping channels, has a utility estimate of +0.416 for shopping mobile for a t-shirt and +0.529 for purchasing a laptop mobile. If the mobile channel offers the same price as alternative channels, the utility estimates are negative (for t-shirt -0.416 and for laptop -0.529). The effect of $10 \%$ less costs of purchasing when using the mobile channel clearly seems to be stronger in the high than in the low involvement context, because the averaged importance for the laptop purchase is $32.031 \%$, whereas it is $22.022 \%$ for the t-shirt purchase, leading to a difference in averaged importance of $10.009 \%$. This is plausible because of the larger savings in absolute terms for high involvement goods when saving a certain percentage of the purchase costs, compared to other channels. Also the t-test result indicates the difference between both involvement levels to be statistically significant with $\mathrm{t}(93)=-4.240$ at $\mathrm{p}<0.001$.

\section{Discussion}

Our findings suggest that situational factors influence the mobile shopping behavior. Cost of purchasing, mobile shop layout and internet connection were identified as the most important situational factors for making planned purchases via the mobile channel. The hypotheses concerning these three situational factors were all supported. Table 5 provides an overview of the results.

Table 5: Summary of Hypotheses and Analysis Results

\begin{tabular}{|c|c|c|}
\hline Hyp. & Situational Factor & Result \\
\hline H1 & $\begin{array}{c}\text { Clear mobile shop } \\
\text { layout }\end{array}$ & $\begin{array}{c}\text { Partially } \\
\text { supported }\end{array}$ \\
\hline H2 & $\begin{array}{c}\text { Availability of } \\
\text { alternative shopping } \\
\text { channel }\end{array}$ & Not supported \\
\hline H3 & Time availability & Sot supported \\
\hline H4 & Level of activity \\
\hline H5 & $\begin{array}{c}\text { Internet connection } \\
\text { quality }\end{array}$ & Supported \\
\hline H6 & $\begin{array}{c}\text { Situational mobile } \\
\text { device use }\end{array}$ & Supported \\
\hline H7 & Cost of purchasing & \\
\hline
\end{tabular}

Situation-dependent lower purchase costs were found to be the major situational influencing factor for using the mobile channel. Thus, temporary discount codes are a possible medium to entice consumers into using the mobile channel. Percentage discounts have a particularly strong effect on high involvement goods. By offering such discounts consumers could get to know a company's mobile shop, and may use it at a later point in time without having a discount code. This is especially useful to discourage consumers from switching to another provider, which has a mobile shop they are familiar with. Moreover, fostering consumers to use the mobile channel may generate additional sales, because using mobile shopping does not imply that consumers do not use other channels anymore. This could especially increase impulse purchases in situations consumers are browsing the internet via their mobile devices.

Internet connection is an important prerequisite for mobile shopping. This would enable consumers to use mobile devices for shopping in even more situations without the risk of purchase process 
interruption. An essential requirement for a userfriendly mobile shop is a clear and self-explanatory layout. This was found to be especially important when selling low involvement products. Therefore, companies should invest money and time in developing and testing an intuitive mobile shop layout.

Although the conducted research provides useful insights, it faces several limitations resulting from either the methodologies applied or the scope of this research. One should bear these in mind when making attempts to apply the research findings in practice. Certain suggestions for further research arise as a result. The questionnaire only measured the stated intentions to use mobile shopping but not actual usage behavior. Additionally, while 94 eligible responses were used for conducting the conjoint analyses, results should be tested with an even larger sample. Due to convenience sampling, the population is not known and representativeness cannot be controlled [52]. To make the rating task as easy and quick as possible, no holdout cases were incorporated. This is clearly a limitation, because they can be used to measure validity [51]. Furthermore, it is possible that heterogeneous subgroups exist that prefer different situational characteristics for shopping mobile in the context of some factors. Thus, cluster analysis should follow the conducted conjoint analyses to identify these groups and their respective preferences [51]. Additionally, the study considered the moderating effect of low involvement products versus high involvement products on the relationship between situational factors and the probability of mobile shopping. However, there are other differentiation approaches to classify products which could also be considered. For example, the moderating effect of hedonic versus utilitarian products could be tested. Furthermore, moderating effects in relation to demographic, cultural or behavioral factors are possible and should be analyzed, because not all people are influenced by situations in the same way.

\section{Conclusion}

This study was carried out to investigate the importance of situational influences on mobile shopping usage. The findings strongly support the need to consider situational factors in order to explain mobile shopping behavior. The conducted conjoint analysis highlights particularly the relevance of product price, internet connection, and mobile shop layout. Thus, the research findings enhance the understanding of why consumers shop mobile. The findings and practical derivations may help organizations to strengthen the mobile channel. However, further research is required in order to understand the relevance of product specific characteristics in relation to mobile shopping.

\section{References}

[1] S. Heitz-Spahn, Cross-channel free-riding consumer behavior in a multichannel environment: An investigation of shopping motives, sociodemographics and product categories, Journal of retailing and consumer services, 20 (2013) 570-578.

[2] E. Brynjolfsson, Y. Hu, M.S. Rahman, Battle of the Retail Channels: How Product Selection and Geography Drive Cross-Channel Competition, Management Science, 55 (2009) 1755-1765.

[3] Statista, Number of smartphone users worldwide from 2014 to 2019 (in millions). 2014.

[4] M. Bick, T.-F. Kummer, Ambient Intelligence, Business \& Information Systems Engineering (BISE), 2 (2010) 317-320.

[5] S. Gao, J. Krogstie, The importance of context towards mobile services adoption., Proceedings of the Fourth International Conference on Mobile Ubiquitous Computing, Systems, Services and Technologies (UBICOMM 2010), IARIA Press, Florence, Italy, 2010, pp. $422-427$.

[6] R.J.-H. Wang, E.C. Malthouse, L. Krishnamurthi, On the go: How mobile shopping affects customer purchase behavior., Journal of Retailing, 91 (2015) 217-234.

[7] Facebook, The thumb is in change, 2015.

[8] eMarketer, Mobile commerce roundup., 2015.

[9] N.F. Taylor, Mobile moments now define the holiday shopping experience., 2015.

[10] M. Groß, Mobile shopping: A classification framework and literature review, International Journal of Retail \& Distribution Management, 43 (2015) 221-241.

[11] J.F. Engel, R.D. Blackwell, P.W. Miniard, Consumer behavior, 6th ed., Dryden Press, Chicago, 1990.

[12] A.J. Badgaiyan, A. Verma, Does urge to buy impulsively differ from impulsive buying behaviour? Assessing the impact of situational factors, Journal of Retailing and Consumer Services, 22 (2015) 145-157.

[13] M. Kukar-Kinney, A.C. Scheinbaum, T. Schaefers, Compulsive buying in online daily deal settings: An investigation of motivations and contextual elements, Journal of business research, 69 (2016) 691-699.

[14] S. Figge, Situation-dependent services - a challenge for mobile network operators, Journal of Business Research, 57 (2004) 1416-1422.

[15] M. Hiltunen, M. Laukka, J. Luomala, Professional mobile user experience, IT Press, Helsinki, Finland:, 2002.

[16] R.W. Belk, Situational variables and consumer behavior, Journal of Consumer Research, 2 (1975) 157164.

[17] M. Khalifa, K.N. Shen, Explaining the adoption of transactional B2C mobile commerce, Journal of Enterprise Information Management, 21 (2008) 110-124.

[18] J.V. Chen, B.-c. Su, A.E. Widjaja, Facebook C2C social commerce: A study of online impulse buying, 
Decision support systems and electronic commerce, 83 (2016) 57-69.

[19] J. Gummerus, M. Pihlström, Context and mobile services' value-inuse, Journal of Retailing \& Consumer Services, 18 (2011) 521-533.

[20] S. Gao, J. Krogstie, K. Siau, Developing an instrument to measure the adoption of mobile services, Mobile Information Systems, 7 (2011) 45-67.

[21] C.H. Wong, H.S. Lee, Y.H. Lim, B.H. Chua, G.W.H. Tan, Predicting the consumers' intention to adopt mobile shopping: An emerging market perspective, International Journal of Network and Mobile Technologies, 3 (2012) 2439.

[22] H.-P. Lu, P.Y.-J. Su, Factors affecting purchase intention on mobile shopping web sites, Internet Research, 19 (2009) 442-458.

[23] K. Yang, Determinants of US consumer mobile shopping services adoption: Implications for designing mobile shopping services, Journal of Consumer Marketing, 27 (2010) 262-270.

[24] A. Holmes, A. Byrne, J. Rowley, Mobile shopping behaviour: Insights into attitudes, shopping process involvement and location, International Journal of Retail \& Distribution, 42 (2013) 25-39.

[25] C.-H. Wong, G.W.-H. Tan, K.-B. Ooi, B. Lin, Mobile shopping: The next frontier of the shopping industry? An emerging market perspective, International Journal of Mobile Communiactions, 13 (2015) 92-112.

[26] F.D. Davis, Perceived usefulness, perceived ease of use, and user acceptance of information technology, MIS Quarterly, 13 (1989) 319-340.

[27] J.-H. Wu, S.-C. Wang, What drives mobile commerce? An empirical evaluation of the revised technology acceptance model, Information \& Management, 42 (2005) 719-729.

[28] J. Aldás-Manzano, C. Ruiz-Mafé, S. Sanz-Blas, Exploring individual personality factors as drivers of $\mathrm{m}$ shopping acceptance, Industrial Management \& Data Systems, 109 (2009) 739-757.

[29] S. Agrebi, J. Jallaisb, Explain the intention to use smartphones for mobile shopping, Journal of Retailing and Consumer Services, 22 (2015) 16-23.

[30] E. Ko, E.Y. Kim, E.K. Lee, Modeling consumer adoption of mobile shopping for fashion products in Korea, Psychology \& Marketing, 26 (2009) 669-687.

[31] R.W. Belk, An exploratory assessment of situational effects in buyer behavior, Journal of Marketing Research, 11 (1974) 156-163.

[32] R.W. Belk, The objective situation as a determinant of consumer behavior, Advances in Consumer Research, 2 (1975) 427-437.

[33] J.A. Cote, J. McCullough, M. Reilly, Effects of unexpected situations on behavior-intention differences: A garbology analysis, Journal of Consumer Research, 12 (1985) 188-194.

[34] R.G. Sandell, Effects of attitudinal and situational factors on reported choice behavior, Journal of Marketing Research, 5 (1968) 405-408.

[35] O.W. DeShields, A. Kara, E. Kaynak, Source effects in purchase decisions: The impact of physical attractiveness and accent of salespersons, International Journal of Research in Marketing, 13 (1996) 89-101.

[36] J.A.F. Nicholls, S. Roslow, S. Dublish, L.B. Comer, Relationship between situational variables and purchasing in India and the USA, International Marketing Review, 13 (1996) 6-21.

[37] S. Roslow, T. Li, J.A.F. Nicholls, Impact of situational variables and demographic attributes in two seasons on purchase behavior, European Journal of Marketing Research, 34 (2000) 1167-1180.

[38] C.W. Park, E.S. Iyer, D.C. Smith, Grocery shopping behavior: The role of store environment and time available for shopping, Journal of Consumer Research, 15 (1989) 422-433.

[39] G. Zhuang, A.S.L. Tsang, N. Zhou, Li, F., J.A.F. Nicholls, Impacts of situational factors on buying decisions in shopping malls, European Journal of Marketing Research, 40 (2006) 17-43.

[40] R. Chocarro, M. Cortiñas, M.-L. Villanueva, Situational variables in online versus offline channel choice, Electronic Commerce and Research Applications, 12 (2013) 347-361.

[41] J.E. Collier, R.S. Moore, A. Horky, M.L. Moore, Why the little things matter: Exploring situational influences on customers' self-service technology decisions, Journal of Business Research, 68 (2015) 703-710.

[42] Deloitte, 2015 global mobile consumer survey US edition: The rise of the always-connected consumer, 2015.

[43] Z. Yang, M. Jun, Consumer perception of e-service quality: From Internet purchaser and non-purchaser perspectives, Journal of Business Strategies, 19 (2002) 1941.

[44] L. Jiang, Z. Yang, M. Jun, Measuring consumer perceptions of online shopping convenience, Journal of Service Management, 24 (2013) 191 - 214.

[45] W.-J. Jih, Effects of Consumer-Perceived Convenience on Shopping Intention in Mobile Commerce: An Empirical Study, International Journal of E-Business Research, 3 (2007) 33-48.

[46] C. Koyuncu, G. Bhattacharya, The impacts of quickness, price, payment risk, and delivery issues on online shopping, The Journal of Socio-Economics, 33 (2004) 241-251.

[47] A. Bryman, Social research methods, 5th ed., Oxford University Press, New York, 2016.

[48] P.E. Green, V. Srinivasan, Conjoint analysis in consumer research: Issues and outlook, Journal of Consumer Research, 5 (1978) 103-123.

[49] V. Toepoel, Doing surveys online, SAGE Publications, London, England, 2016.

[50] M. Denscombe, The good research guide: For smallscale social research projects 5th ed., Open University Press, Maidenhead, England, 2014.

[51] K. Backhaus, B. Erichson, W. Plinke, R. Weiber, Multivariate Analysemethoden: Eine anwendungsorientierte Einführung, 14th ed., Springer Gabler, Berlin, Germany, 2015.

[52] F.J. Gravetter, L.-A.B. Forzano, Research methods for the behavioral sciences, 5th ed., Cengage Learning, Stamford, CT, 2015. 